\title{
MATHEMATICAL MODEL OF GAS, POWDER AND BED FLOW IN METALLURGICAL SHAFT FURNACES
}

\begin{abstract}
This paper presents the second phase of model investigations. In the first phase research into flow for the system "gas transporting powder - moving packed bed" was conducted in the physical modeling. The influence of bed, powder and gas parameters on values of interaction forces and phenomena occurring in investigated system was defined.

The article discusses the successive stage of investigations into gas flow carrying the powder through the descending packed bed. The research was performed with the application of mathematical modeling after tests with a physical model in use had been accomplished. The elaborated mathematical model was used to calculate resistance values of gas flow carrying the powder through the descending packed bed, masses of 'static' and 'dynamic' powders as well as total mass of powder holdup in the bed. Then the verification of the model was done comparing the obtained results with those from the physical model.
\end{abstract}

Keywords: mathematical modeling, metallurgical shaft furnace, system: descending packed bed - gas - powder, resistance of gas flow, bed suspension.

\section{List of symbols}

D - diameter of column, m,

$\mathrm{d}_{\mathrm{e}}-\quad$ equivalent diameter for packed bed particles and static powder, $\mathrm{m}$,

$\mathrm{d}_{\mathrm{p}}-\quad$ powder diameter, $\mathrm{mm}$,

$\mathrm{d}_{\mathrm{z}}$ - diameter of a packed particle, $\mathrm{m}$,

$\mathrm{F}_{\mathrm{g}-\mathrm{p}}$ - interaction force between gas and pieces of dynamic powder, $\mathrm{Pa} / \mathrm{m}$,

$\mathrm{F}_{\mathrm{g}-\mathrm{z}}$ - interaction force between gas and pieces of bed coated by static powder, $\mathrm{Pa} / \mathrm{m}$,

$\mathrm{F}_{\mathrm{p}-\mathrm{z}}-\quad$ interaction force between dynamic powder particles and bed particles coated by static powder, $\mathrm{Pa} / \mathrm{m}$,

$\mathrm{F}_{\mathrm{z}-\mathrm{z}}$ - interaction force between bed particles, $\mathrm{Pa} / \mathrm{m}$,

$\mathrm{F}_{\mathrm{k}}$ - additional pressure loss coefficient, -,

$\mathrm{F}_{\mathrm{r}}$ - $\quad$ Froude number, -,

L - length segment (height) of packed bed (layers of material), $\mathrm{m}$,

$\mathrm{M}_{\mathrm{p}}$ - powder flow intensity, $\mathrm{kg} / \mathrm{s}$,

$\mathrm{p}$ - pressure, $\mathrm{Pa}$,

$R_{d}$ - detaching rate of powder from particle surface, $\mathrm{kg} /$ $\mathrm{m}^{3} \mathrm{~s}$,

$\mathrm{R}_{\mathrm{s}}$ - $\quad$ sticking rate of powder to particle surface, $\mathrm{kg} / \mathrm{m} 3 \mathrm{~s}$,

$r$ - radius of measurement, $m$,

$\mathrm{U}_{\mathrm{g}}$ - $\quad$ gas velocity, $\mathrm{m} / \mathrm{s}$,

$\mathrm{U}_{\mathrm{p}}$ - $\quad$ powder velocity, $\mathrm{m} / \mathrm{s}$,

$\mathrm{U}_{\mathrm{z}}-\quad$ bed particles velocity, $\mathrm{m} / \mathrm{s}$,

$\mathrm{V}_{\mathrm{g}}$ - volume gas flow intensity, $\mathrm{m}^{3}$,

$\varepsilon_{0}-\quad$ void fraction in packed bed, -,

$\varepsilon_{\mathrm{g}} \quad$ - volume fraction of gas, -,

$\varepsilon_{\mathrm{pd}}-\quad$ volume fraction of the dynamic hold up of powders, -,

$\varepsilon_{\mathrm{ps}}-\quad$ volume fraction of the static hold up of powders, -, $\varepsilon_{\mathrm{z}}-\quad$ volume fraction of bed, -,

$\varphi_{p}-\quad$ shape factor of a powder, -,

$\mu_{\mathrm{zz}}{ }^{-} \quad$ coefficient of friction between bed particles, $\mathrm{Pa} \cdot \mathrm{s}$,

$\rho_{\mathrm{g}}-\quad$ density of gas, $\mathrm{kg} / \mathrm{m}^{3}$,

$\rho_{\mathrm{p}}-\quad$ density of a powder, $\mathrm{kg} / \mathrm{m}^{3}$,

(0-100), (100-400), - indexes indicting corresponding column height segment.

\section{Introduction}

The flow of gas and powder through the descending packed bed occurs during various different technological processes. In metallurgy, specially in metallurgical shaft furnaces, such multiphase flow radically affects the operation of these reactors. Blast furnace is an example of the most complex of all metallurgical shaft furnaces. Among the parameters which influence the flow of the processes inside shaft furnaces are gas flow velocity and the amount of powder content. Apart from that the properties of blast furnace sinter are also changed in the real blast furnace process. In particular, there is a decrease in the porosity of sinter and its softening phenomenon takes place, which affects the rate of reduction [1] and may affect the distribution of gas velocity and the resulting distribution of powder. The phenomenon of sinter softening was disregarded in further analysis, only limiting the analysis to the shaft where the sinter is in form of pieces in solid state. The parameters mentioned above refer to gas and powder and determine the predisposition to the deposition of powder in bed which (in some cases) may lead to its suspension.

Therefore all the phenomena which occur inside the metallurgical reactor should be well recognized and specified.

* SILESIAN UNIVERSITY OF TECHNOLOGY, INSTITUTE OF METALS TECHNOLOGY, 8 KRASINSKIEGO STR., 40-019 KATOWICE, POLAND

" Corresponding author: Bogdan.Panic@polsl.pl 
However, operational conditions and high temperature inside metallurgical reactors make it hard and frequently impossible to collect appropriate data from a working metallurgical furnace. Present development of laboratory equipment and numerical methods are the means to obtain the data easily with the use of physical and mathematical modeling of the metallurgical processes. Numerous investigations which help to study the processes inside metallurgical reactors carried out with mathematical modeling have been described in literature [2-9].

Generally there are two main methods of mathematical modeling of fluid flows in shaft metallurgical furnaces: Continuum and DEM. Continuum treats all phases as continuous medium. DEM considers the elements of dispersed phase individually and tracks their story during the flow in the analyzed area. Suspensions of solid particles in fluids are one of the illustrations of such systems. Thus the DEM seems highly effective in modeling of the flow of solid particles. However, at high concentrations and with large number of particles it is not advantageous to record the parameters of all particles.

Despite rapid development in computer technology the simulation method of the processes taking place inside shaft metallurgical furnaces is too slow to be effectively applied. Therefore Continuum approach is being used at present [5]. The article describes next investigation stage of gas flow carrying the powder through descending packed bed. The investigations have been performed with the application of mathematical modeling after the tests with physical model in use had been accomplished. The results of laboratory research carried out with the use of the following systems: high alumina sphere bed - iron powder and blast furnace pellets iron powder, are presented in [10]. The mathematical model described here is based on the Continuum method and verified according to the obtained laboratory results. The aim of the investigations was:

- elaboration of the mathematical model of two-phase flow (gas+powder) through the descending bed taking into account powder content in gas, type and size of powder particles as well as type and size of bed pieces;

- calculation of the flow resistance values of gas carrying powder through the descending packed bed, masses of the "static" and "dynamic" powders as well as total mass of powder holdup in the bed. This was done with the application of the elaborated mathematical model for each measurement point of the carried out experiments.

- verification of the model basing on the obtained test results of the physical model.

\section{Mathematical model}

With the previous investigations on two-phase flow (gas+powder) through the descending packed bed [8] in mind, (compare paper [6]), the mathematical model which analyzed four types of resistances was elaborated. Figure 1 shows the geometry of the measurement system. Segment measurement method was used during laboratory tests. Static pressure distribution in the function of the experimental column radius has been performed at four levels of the column height (levels: 0,$25 ; 0,38 ; 0,50 ; 0,75)$ and the pressure differences were measured at three segments between these levels (Fig.1). The method enabled the identification of the area where most intensive powder hold up occurs.

Thus the following have been considered at the process of model development:

1. Total experimental volume of the column includes: experimental volume of the lower segment of $0,1 \mathrm{~m}$ height (with intensive powder hold up) and experimental volume of the upper segment of $0,3 \mathrm{~m}$ height ( with less intensive powder hold up).

2. Packed layer consists of bed particles coated by "static" powder and takes appropriate volume for a given height segment.

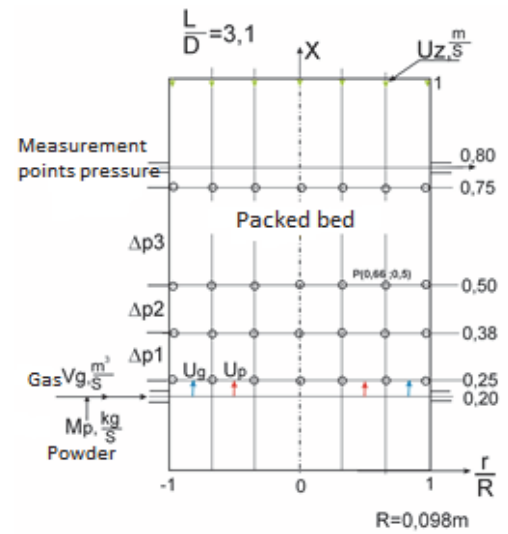

Figure 1. Measurement system with descending packed bed

The fundamental equations of continuity and momentum for gas, powder and bed are presented below:

Gas

Continuity equation:

$$
\frac{d}{d x}\left(\varepsilon_{g}\left(r_{0}, x\right) \rho_{g} \vec{U}_{g}^{\prime}\left(r_{0} x\right)\right)=0
$$

where

$$
U_{g}^{\prime}(r o, x)=\frac{U_{g}}{\varepsilon_{g}\left(r_{0}, x\right)}
$$

Momentum equation:

$$
\begin{gathered}
\frac{d}{d x}\left(\varepsilon_{g}\left(r_{0}, x\right) \rho_{g} \vec{U}_{g}^{\prime}\left(r_{0}, x\right) \mid \vec{U}_{g}^{\prime}\left(r_{0}, x\right)\right)= \\
-\frac{d}{d x}\left(p\left(r_{0}, x\right) \varepsilon_{g}\left(r_{0}, x\right)\right)-\left(\vec{F}_{g-z}\left(r_{0}, x\right)+\vec{F}_{g-p}\left(r_{0}, x\right)\right.
\end{gathered}
$$

Powder

Continuity equation:

$$
\frac{d}{d x}\left(\varepsilon_{p d}\left(r_{0}, x\right) \rho_{p} \vec{U}_{p}^{\prime}\left(r_{0}, x\right)\right)=(R s-R d)
$$

where

$$
U_{p}^{\prime}(r 0, x)=\frac{U_{p}}{\varepsilon_{p d}\left(r_{o}, x\right)}
$$

Momentum equation: 


$$
\begin{gathered}
\frac{d}{d x}\left(\varepsilon_{p d}\left(r_{0}, x\right) \rho_{p} \vec{U}_{p}^{\prime}\left(r_{0}, x\right)\left|\vec{U}_{p}^{\prime}\left(r_{0}, x\right)\right|\right) \\
=\left(\vec{F}_{g-p}\left(r_{0}, x\right)+\vec{F}_{p-z}\left(r_{0}, x\right)\right)
\end{gathered}
$$

\section{Packed bed}

Continuity equation:

$$
\frac{d}{d x}\left(\left(\varepsilon_{z}+\varepsilon_{p s}\left(r_{0}, x\right)\right) \rho_{z p s}\left(r_{0}, x\right) \vec{U}_{z}^{\prime}\right)=(R d-R s),
$$

where

$$
U_{z}^{\prime}(r o, x)=\frac{U_{z}}{\varepsilon_{z}+\varepsilon_{p s}\left(r_{o}, x\right)}
$$

Momentum equation:

$$
\begin{aligned}
& \frac{d}{d x}\left(\left(\varepsilon_{z}+\varepsilon_{p s}\left(r_{0}, x\right)\right) \rho_{z p s}\left(r_{0}, x\right) \vec{U}_{z}\left|\vec{U}_{z}\right|\right) \\
= & \vec{F}_{g-z}\left(r_{0}, x\right)+\vec{F}_{p-z}\left(r_{0}, x\right)+\vec{F}_{z-z}\left(r_{0}, x\right)
\end{aligned}
$$

Equations describing resistances $F_{g-z}, F_{g-p}$, and $F_{p-z}$ are presented in [6]. The resistance caused by the interaction forces between particles of the descending bed is described by the Stokes' equation for each separate falling particle in fluid. After appropriate transformations the equation takes the form:

$$
\vec{F}_{z-z}=18\left(\varepsilon_{z}+\varepsilon_{p s}\right) \frac{\mu_{z z} \vec{U}_{z}}{d_{e}^{2}}
$$

As the outcome of the performed analysis $0,5 \mathrm{~Pa} \mathrm{~s}$ was adopted as the value of coefficient $\mu_{z z}$ which is the optimal value in simulation of the experimental results. The solution procedure of the adopted model calls for further search of correlation between indicator $\varepsilon_{p d}$ and $\varepsilon_{p s}$ as well as correlation between coefficient $F_{k}$ and Froude's number.

Dependence $\varepsilon_{p s}=f\left(\varepsilon_{p d}\right)$ for research volume of the lower section of the column with a height of $0,1 \mathrm{~m}$ - is expressed in the equation in the form:

$$
\varepsilon_{p s(0-100)}=-0,0857 * \ln \left(\varepsilon_{p d(0-100)}\right)-0,2321
$$

and in case of the research volume of the upper section of the column with a height of $0,3 \mathrm{~m}$ - equation:

$\varepsilon_{p s(0-100)}=21,08 *\left(\varepsilon_{p d(0-100)}\right)^{2}-4,6744^{*}\left(\varepsilon_{p d(0-100)}\right)+0,1208$

Figures 2 show relation $\varepsilon_{p s}=\mathrm{f}\left(\varepsilon_{p d}\right)$.

Dependence $F_{k}=f(F r)$ for research volume of the lower section of the column with a height of $0,1 \mathrm{~m}$ is expressed in the equation in the form:

$$
F_{k}=2,6592 \mathrm{Fr}^{-2,0723} \text {, }
$$

and in case of the research volume of the upper section of the column with a height of $0,3 \mathrm{~m}$ - equation in the form:

$$
F_{k}=0,2303 F^{-2,5809}
$$

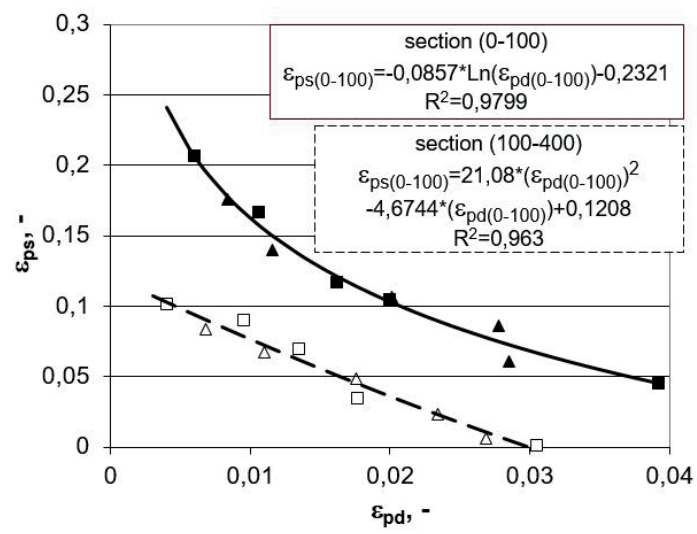

Fig. 2. Relationship between volume friction of „static" powder " $\varepsilon_{\mathrm{ps}}$ and volume friction of "dynamic" powder epd for model system with high alumina or blast furnace pellets + iron powder

Figures 3 show relation $F_{k}=\mathrm{f}(F r)$.

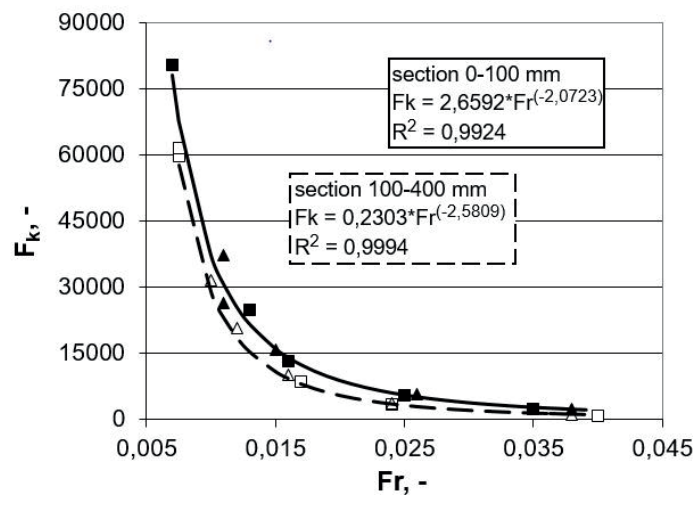

Fig. 3..Relationship between additional pressure drop coefficient due to gravitational force of powder and friction and collision between powder and bed particles $\mathrm{F}_{\mathrm{k}}$ and Froude number for model system with high alumina or blast furnace pellets + iron powder

All the calculated and measured values of flow resistance and volume indicators of "static" powder, "dynamic" powder and total volume of mass powder have been plotted on the charts. Verification results are presented in Figs. 4-7.

List of frequently used marks

TABLE 1

\begin{tabular}{|c|c|c|c|c|c|c|c|}
\hline \hline $\boldsymbol{L}_{(0-100 \mathrm{~mm})}$ & $\boldsymbol{L}_{(100-400 \mathrm{~mm})}$ & $\boldsymbol{d}_{z}, \mathbf{m}$ & $\boldsymbol{\varepsilon}_{0},-$ & $\boldsymbol{d}_{\boldsymbol{p}}, \mathbf{m m}$ & $\boldsymbol{\Phi}_{p},-$ & $\boldsymbol{G}, \mathbf{k g} / \mathbf{m}^{2} \mathbf{s}$ & Notes \\
\hline $\boldsymbol{\Delta}$ & $\Delta$ & 0,013 & 0,45 & $0,090-0,130$ & 0,76 & 0,45 & $\begin{array}{c}\text { bed: spheres } \mathrm{Al}_{2} \mathrm{O}_{3} \\
\text { powder: iron powder }\end{array}$ \\
\hline $\boldsymbol{\square}$ & $\square$ & 0,016 & 0,48 & $0,090-0,130$ & 0,76 & 0,45 & bed: blast furnace pellets powder: iron powder \\
\hline
\end{tabular}




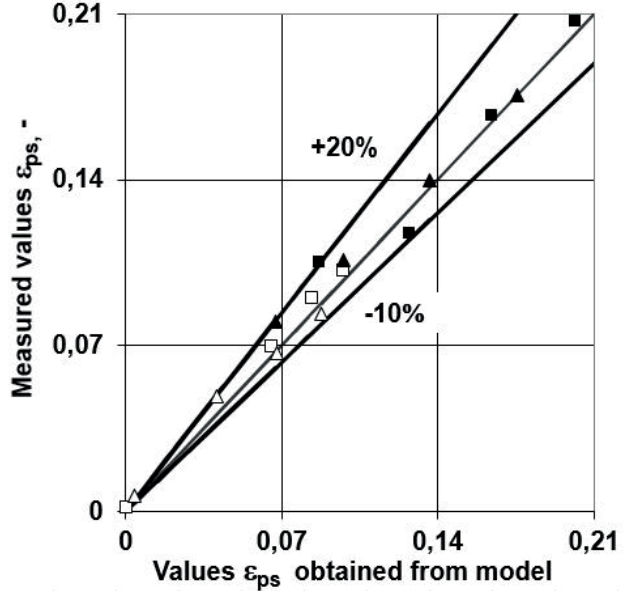

Fig. 4. Comparison of experimental values of „static" powder volume friction for two phase (gas+powder) flow through moving, granular bed with values calculated from model

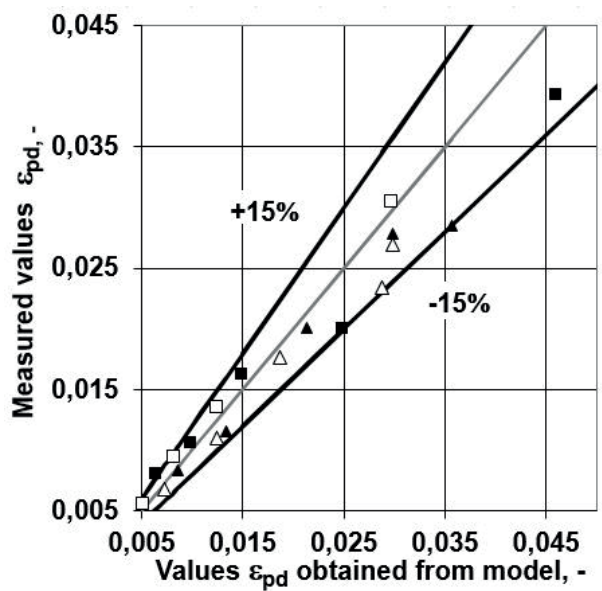

Fig. 5. Comparison of experimental values of „dynamic” powder volume friction for two phase (gas+powder) flow through moving, granular bed with values calculated from model

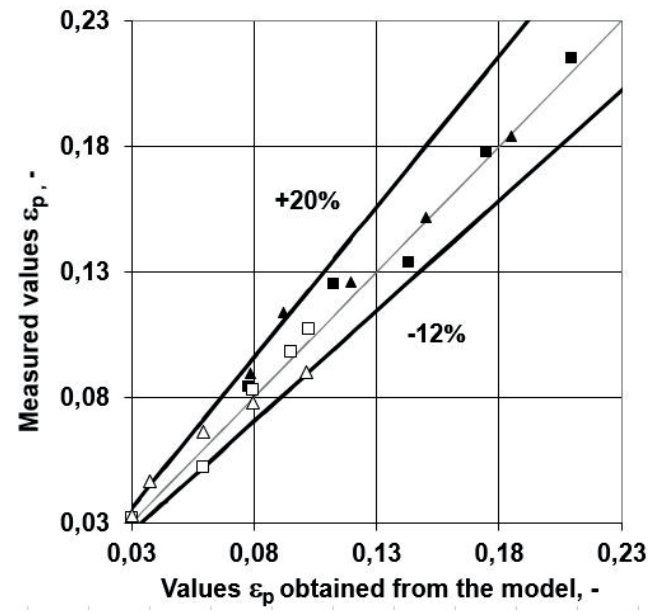

Fig. 6. Comparison of experimental values of volume friction of total powder hold up in bed for two phase (gas+powder) flow through moving, granular bed with values calculated from model

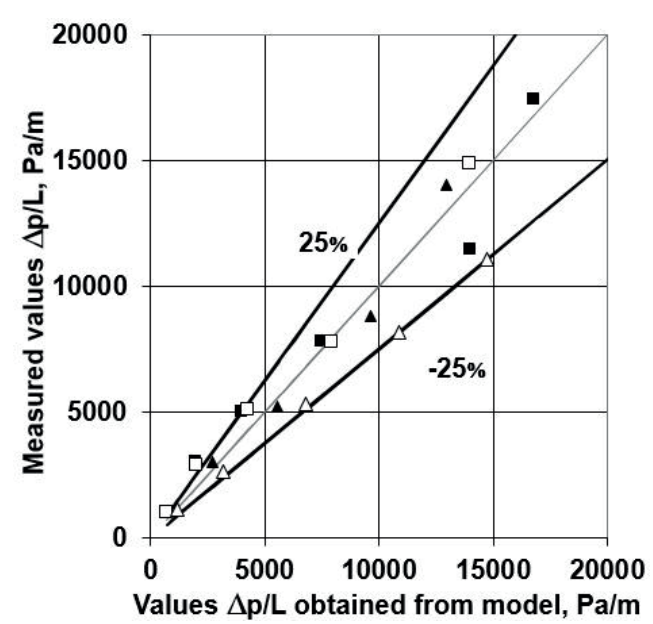

Fig. 7. Comparison of experimental values of flow resistance for two phase (gas+powder) flow through moving, granular bed with values calculated from model

In the majority of cases the calculated values do not differ from the measured values by more than $15 \%$.

\section{Summary and conclusions}

The mathematical model which enables the calculation of the powder mass held up in the bed as well as the flow resistance values of gas for two-phase flow (gas+powder) through the descending packed bed has been elaborated. The mathematical model described here is based on the Continuum method and verified according to the obtained laboratory results. Four types of partial resistances between gas, bed and powder $\left(F_{g-z}\right.$, $\left.F_{g-p}, F_{p-z}, F_{z-z}\right)$ have been considered. The model was solved taking into account the balance of mass and movement, fluid dynamics equation as well as division of fluids into "static" and "dynamic". The factor which significantly improves the agreement between the results calculated and the results measured is the author's own definition of:

- $\quad$ equation which describes the resistance caused by impact strength between the particles of descending bed (10),

- correlation between indicator $\varepsilon_{p d}$ and $\varepsilon_{p s}$ (11)(12) as well as correlation between coefficient $F_{k}$ and Froude's number (13) (14).

In the majority of cases the calculated values from the model do not differ from the obtained measured values by more than $15 \%$. The maximum difference does not exceed $25 \%$.

\section{REFERENCES}

[1] L. Król, J. Dankmeyer - Łączny, J. Węgrzyn, Steel Research 58, 6, 257-261 (1987).

[2] J. Pieprzyca, Z. Kudliński, Stahl \& Eisen, 1, 51-53 (2004).

[3] Z. Zhou, H. Zhu, A. Yu, P. Zulli, ISIJ International 50, 4, $515-$ 523 (2010).

[4] Z. Zhou, H. Zhu, B. Wright, A. Yu, P. Zulli, Powder Technology 208, 3, 72-85 (2011).

[5] G.L. Qing, L. Ma, X.S. Zhang, J.L. Zhou, M. Kuwabara, 
Ironmaking and Steelmaking 37, 7, 546-552 (2010).

[6] B. Panic, Metalurgija 50, 3, 183-187 (2011).

[7] R.S. Nick, A. Tilliander, T.L.I. Jonsson, P. G. Jönsson, ISIJ International 53, 6, 979-987 (2013).

[8] S. Ueda, S. Natsui, H. Nogami, J-i. Yagi, T. Ariyama, ISIJ
International 50, 7, 914-923 (2010).

[9] K. Chattopadhyay, M. Isac, R.I.L. Guthrie, Ironmaking and Steelmaking 37, 8, 554-561 (2010).

[10] B. Panic, Archives of Metallurgy and Materials 59, 2, 796-800 (2014).

Received: 20 May 2015 . 
